\title{
LA "CASA DE LA AMISTAD": MODOS DE CONSTRUIR Y SIGNIFICAR EL HOGAR PROPIO EN JÓVENES DE LA CIUdAd DE BUENOS AIRES
}

\author{
MAgdalenA FelicE ${ }^{1}$
}

\begin{abstract}
RESUMEN
Este artículo analiza, desde una estrategia cualitativa-interpretativa, las experiencias de construcción de un hogar propio en jóvenes de sectores medios de la Ciudad de Buenos Aires que se fueron a vivir con amigos. Entre los resultados, se destaca que los amigos constituyen un soporte afectivo fundamental, en tanto la asociación con los pares permite afrontar el desafío de irse de la casa familiar de origen y construir un hogar propio. A su vez, la "casa de la amistad" se presenta como un espacio de sociabilidad juvenil que contribuye a la conformación de la subjetividad.
\end{abstract}

PALABRAS CLAVE: TRANSICIONES JUVENILES, HOGAR, AUTONOMÍA

\footnotetext{
${ }^{1}$ Argentina. Magister en Sociología Económica, Instituto de Altos Estudios Sociales, Universidad Nacional de San Martín (IDAES/UNSAM), Buenos Aires, Argentina. Licenciada y Profesora en Sociología de la Universidad de Buenos Aires, Argentina. Doctoranda en el Programa de Sociología del IDAES/UNSAM. Becaria del Consejo Nacional de Investigaciones Científicas y Técnicas (CONICET) de la República Argentina en el Instituto de Investigaciones Gino Germani (IIGG) de la Facultad de Ciencias Sociales, Universidad de Buenos Aires.

Este artículo recoge resultados de una investigación realizada durante 2013 y 2015 en el marco de la tesis de maestría en Sociología Económica. Email: magdalenafelice@gmail.com.
} 
118 La "casa de la amistad": Modos de construir y significar el hogar propio en jóvenes de la Ciudad de Buenos Aires

\title{
A "CASA DA AMIZADE": MANEIRAS DE CONSTRUIR E SIGNIFICAR O LAR PRÓPRIO EM JOVENS DA CIDADE DE BUENOS AIRES
}

\begin{abstract}
RESUMO
Este artigo analisa, a partir de uma estratégia qualitativa - interpretativa, as experiências de construção de um lar próprio em jovens de classe média da Cidade de Buenos Aires que foram morar com amigos. Entre os resultados, destaca que os amigos constituem um suporte afetivo fundamental, enquanto a associação com os pares permite afrontar o desafio de deixar a casa da família de origem e construir um lar próprio. Ao mesmo tempo, a "casa da amizade" é apresentada como um espaço de sociabilidade juvenil que contribui para a conformação da subjetividade.
\end{abstract}

PALAVRAS-CHAVE: TRANSIÇÕES JUVENIS - LAR - AUTONOMIA.

\section{“THE HOUSE OF FRIENDSHIP": WAYS TO BUILD AND MEAN THE OWN HOME IN YOUNG PEOPLE OF THE CITY OF BUENOS AIRES}

\begin{abstract}
On the basis of a qualitative-interpretative strategy, the article analyzes the experiences of young middle class people living in a shared house from the City of Buenos Aires during the process of building their own home. Among the results, it is highlighted that friends constitute a fundamental emotional support, while the partnership with peers allows facing the challenge of leaving the origin family home and building a home of their own. In turn, the "house of friendship" is presented as a space of youth sociability that contributes to the conformation of subjectivity.

KEYWORDS: YOUTH TRANSITIONS - HOME - AUTONOMY
\end{abstract}




\section{INTRODUCCIÓN}

En la actualidad la salida del hogar familiar de origen y la construcción de un hogar propio resulta un proceso complejo, prolongado y contradictorio (Ciganda y Pardo, 2014; Ferraris, 2015). En la Ciudad de Buenos Aires (CABA), al igual que en otras metrópolis latinoamericanas, acceder a una vivienda es una de las dificultades que deben afrontar quienes se proponen abandonar el nido. Los jóvenes ${ }^{2}$ de generaciones recientes atraviesan su juventud en un contexto histórico en el que han empeorado las condiciones de acceso a una vivienda para distintos sectores de la población. El aumento del precio de los inmuebles, la restricción de los créditos hipotecarios y el incremento del costo de los alquileres, en un contexto de desregulación del mercado inmobiliario, son algunos de los factores que contribuyen a explicar la agudización de esta cuestión durante los últimos diez años ${ }^{3}$ (Baer y Kauw, 2016). Esta problemática se intensifica debido a las mayores limitaciones que afronta la población juvenil respecto de la adulta para insertarse en empleos formales, con acceso a la protección social (Busso y Pérez, 2015; Ferraris y Martínez Salgado, 2015). En este sentido, construir un hogar propio se presenta como una carrera con obstáculos y desvíos.

\footnotetext{
${ }^{2}$ En este artículo utilizamos los términos "los jóvenes" y "amigos", entre otros, para referirnos tanto a mujeres como a varones. Esta decisión no desconoce los efectos visibilizadores en cuanto a las cuestiones de género que pueden tener los usos "los y las"; simplemente, se toma a los efectos estilísticos.

${ }^{3}$ De acuerdo con el estudio de Baer y Kauw (2016) sobre el mercado inmobiliario y el acceso a la vivienda formal en la CABA, mientras que en 2009 se necesitaban 8,5 años de ingresos medio para comprar un departamento de dos ambientes a estrenar en un barrio de la CABA, en 2013 se requerían 11,9. El mercado de alquiler tampoco presenta un panorama alentador. El alquiler medio de un departamento usado de tres ambientes se incrementó entre un $47 \%$ y un $57 \%$ entre el 2011 y el 2013; esto insumía entre un 30\% a un 50\% de un sueldo promedio de la CABA (Reporte Inmobiliario, 2013). Un hábito particular del mercado inmobiliario argentino que agudiza aún más la problemática habitacional es el empleo del dólar como referente para la cotización de los bienes inmobiliarios y la operación de transacciones de compra-venta.
} 
120 La "casa de la amistad": Modos de construir y significar el hogar propio en jóvenes de la Ciudad de Buenos Aires

En Latinoamérica, una serie de investigaciones socio-demográficas destacan que, si bien bajo estas condiciones se registra cierta postergación de la salida del hogar de origen entre las generaciones recientes, también se observa un fenómeno emergente, por sobre las variaciones en el calendario: el crecimiento en la formación de hogares no familiares, esto es, unipersonales u horizontales (compartidos con amigos o compañeros), en particular entre jóvenes con mayor nivel educativo (Ciganda y Pardo, 2014; Echarri y Pérez Amador, 2007; Ferraris, 2015). En la CABA, el Observatorio de la Juventud (2016), a partir de datos de la Encuesta Joven 2014 para la población de 15 a 29 años, expresa estas tendencias regionales a nivel local. De acuerdo con su infografía, si bien sólo el 10, 7\% de los jóvenes que tienen entre 15 y 19 años vive fuera del hogar de origen, este porcentaje aumenta a $39,8 \%$ entre los jóvenes de 20 a 24 años y alcanza al 67,2\% de quienes tienen entre 25 y 29 años. Mientras 1 de cada $3(36,4 \%)$ se fue a vivir en pareja (con o sin hijos), 2 de cada $3(63,6 \%)$ viven solos, con amigos u otros familiares. Cabe advertir que, entre aquellos que finalizaron sus estudios secundarios, el $71 \%$ se fue a vivir bajo estas modalidades, y sólo el 29\% formó un hogar en pareja (con o sin hijos); en cambio, entre quienes no completaron estos estudios, más de la mitad se juntó con su pareja o formó un hogar familiar $(56,3 \%)$, y el resto $(43,7 \%)$ se fue a vivir solo, con amigos u otros familiares.

En este marco, el objetivo del presente artículo es explorar, desde la perspectiva de sus protagonistas, los modos de construir y significar el hogar propio conformado con amigos.

A partir de una estrategia cualitativa-interpretativa basada en entrevistas en profundidad orientadas biográficamente, nos detenemos en los relatos y las experiencias de 20 jóvenes de familias de sectores medios de la CABA que se fueron de su casa de origen a vivir con amigos. ¿Cómo construyeron este tipo de hogar propio? ¿Qué rol cumplen los vínculos de amistad en el en este proceso? ¿Cómo son los arreglos de convivencia? ¿Qué significaciones asume 
la "casa de la amistad" en la experiencia juvenil? La perspectiva analítica de la individuación ${ }^{4}$ brinda herramientas productivas para abordar las experiencias juveniles ${ }^{5}$. En particular, consideramos las nociones de "soportes", "pruebas" y "reflexividades" (Martuccelli, 2007) para analizar, en los relatos biográficos, los modos de construir y de significar un hogar propio.

De acuerdo con Martuccelli (2007), los "soportes"-afectivos, materiales y simbólicos- constituyen medios por los cuales el individuo enfrenta distintas "pruebas" sociales y llega a "sostenerse" en el mundo. Es imposible pensar en un individuo sin un conjunto de soportes, dado que ningún individuo se sostiene solo. Estos soportes pueden presentarse tanto de manera activa (movilizados de modo consciente por el sujeto) como indirecta o no consciente (en tanto consecuencia colateral de su entramado social y existencial). Las "pruebas", por su parte, consisten en “...desafíos históricos, socialmente producidos, culturalmente representados, desigualmente distribuidos que los individuos están obligados a enfrentar en el seno de un proceso estructural de individuación" (Araujo y Martuccelli, 2010: 83). Así, los individuos “...constituyen un entorno existencial combinando relaciones u objetos, experiencias o actividades diversas, próximas o lejanas, que, en la ecología así constituida, van o no a dotarse de significaciones absolutamente singulares" (Martuccelli, 2007:81). Este "tejido existencial y social elástico" configura "su" verdadero mundo, que cobra especial resignificación a partir del relato que los individuos logran elaborar sobre él.

\footnotetext{
${ }^{4}$ Esta perspectiva se centra a nivel del individuo y analiza la vida social -así como los principales cambios societales- a partir del individuo y sus experiencias (Martuccelli, 2007; Singly, 2009). El interrogante que orienta esta propuesta analítica gira en torno "al tipo de individuo que es estructuralmente fabricado por una sociedad en un período histórico" (Araujo y Martuccelli, 2010: 83).

${ }^{5}$ En el contexto argentino, las investigaciones del equipo de Di Leo y Camarotti (2010 y 2016) constituyen una referencia ineludible de los estudios sociológicos sobre los soportes y las pruebas que intervienen en los procesos de individuación, en particular de los jóvenes
} 
122 La "casa de la amistad": Modos de construir y significar el hogar propio en jóvenes de la Ciudad de Buenos Aires

En este artículo planteamos que, si bien el apoyo familiar resulta cada vez más fundamental en el acceso a una vivienda ${ }^{6}$, en la experiencia juvenil de sectores medios las asociaciones y ayudas entre pares de generación, como por ejemplo los amigos, constituyen un soporte fundamental para enfrentar la encrucijada entre el deseo de "irse a vivir solo" -entendido como "irse de la casa de origen"- y la dificultad de concretarlo de manera individual por razones económicas. Sin compromisos familiares asociados a la vida adulta, con "crédito temporal y social" (Margulis y Urresti, 1998), en estos jóvenes de sectores medios los amigos constituyen la "familia ad hoc", con quienes se juntan, se encuentran y comparten su experiencia cotidiana. A explorar tales arreglos de convivencia juveniles se orienta el presente artículo.

\section{TRANSICIONES EN LA EXPERIENCIA JUVENIL}

Todas las sociedades producen un sistema de enclasamiento según la edad, es decir, compartimentan la experiencia temporal vital de los sujetos en períodos de vida y definen grupos de edad a los que atribuyen propiedades. La edad, junto con el sexo, es base -o materia significante- de clasificaciones sociales y estructuraciones de sentido; de modo que toda categoría etaria resulta significativa porque su uso conduce a un marco de sentidos (Feixa, 1998; Margulis y Urresti, 1996). Ahora bien, cada sociedad -o época- tiene sus propios modos de ordenar la temporalidad y producir grupos de edad o etapas de la vida. Los grupos etarios son “... un constructo modelado por la cultura, cuyas formas y contenidos son cambiantes en el espacio, en el tiempo y en la estructura social" (Feixa, 1998: 16).

El tiempo biográfico de la juventud constituye una experiencia temporal particular, en tanto supone una referencia a la edad entendida como un dato

\footnotetext{
${ }^{6}$ En relación con la intervención de las redes familiares en el acceso a la vivienda de familias de sectores medios, pueden consultarse en el contexto argentino los trabajos de Cosacov (2014) y Di Virgilio y Gil y de Anso (2012).
} 
duro y objetivo que surge del posicionamiento cronológico. Como característica general, los jóvenes disponen de un "crédito temporal" más extendido que el de las generaciones mayores (Margulis y Urresti, 2008: 18). Margulis y Urresti (2008) postulan la categoría "moratoria vital" para referirse a esta disponibilidad de tiempo diferencial que supone un conjunto menor de compromisos asumidos y, por ende, una forma de habitar el presente menos condicionada y determinada por decisiones anteriores ${ }^{7}$. De acuerdo con los autores, esta condición existencial -que se deriva de la edad- nos habla de un modo de situarse en la vida, en la que ésta aparece como breve, "a estrenar" y en proceso de construcción. En este sentido, la experiencia de los sectores jóvenes se distingue de aquella de los no jóvenes, entre quienes “... el abanico de posibilidades de realización personal y de performances vitales está reducido por la serie de acontecimientos que se ha ido estructurando con cada elección realizada y tiende a cerrarse con el paso de los años" (Margulis y Urresti, 1998: $10)$.

En este marco, ser joven también involucra una experiencia histórica particular, la de su generación, en la medida que tener una edad y no otra implica haber sido socializado en un momento histórico determinado con una configuración social específica (Mannheim, 1993). La particularidad de los jóvenes como actores históricos radica en el hecho de ser "nativos del presente" (Urresti, 2011). Los jóvenes se incorporan a la sociedad en el presente, y en él construyen sus mundos de vida: forman su personalidad, confeccionan su cultura y organizan su mundo perceptivo y sensible. La generación de pertenencia “... no es una simple coincidencia en la fecha de nacimiento, sino una verdadera hermandad frente a los estímulos de una época" (Margulis y Urresti, 1998: 26).

\footnotetext{
${ }^{7}$ Los autores construyen este argumento en diálogo con el texto de Bourdieu "La 'juventud' es sólo una palabra" (2000) para enfatizar que la "juventud" no es sólo una construcción discursiva cargada de valores. Para ampliar este debate, véase Margulis y Urresti (2008).
} 
124 La "casa de la amistad": Modos de construir y significar el hogar propio en jóvenes de la Ciudad de Buenos Aires

La construcción social de las etapas de la vida sobre la base de la edad también involucra un sistema de promoción, esto es, una serie de pasos o vías que conducen, socialmente hablando, de un edad a la otra. En particular, la transición a la vida adulta remite a un pasaje temporal -social y culturalmente definido- que lleva desde la infancia hacia la adultez. En las sociedades occidentales contemporáneas, este proceso supone la concepción de dos segmentos diferenciados: la adolescencia y la juventud. Esto quiere decir que, en lugar de pensarse como un rito de pasaje, la transición a la vida adulta se establece como una experiencia temporal particular que, procesada por la historia y la cultura, configura una nueva etapa de la vida (la juventud) a la que se le atribuyen estatus y roles sociales específicos.

Este proceso de invención de la juventud como etapa de la vida tiene coordenadas socio-históricas precisas: se desarrolló en los países occidentales a finales del siglo XIX, en el marco de los procesos de modernización de las sociedades europeas, en relación con “... la expulsión de los jóvenes del mercado de trabajo, la extensión de la escolaridad obligatoria y del servicio miliar, la nuclearización de la familia y el surgimiento de entidades especialmente orientadas a la juventud" (Feixa, 1998: 4). Bajo estas condiciones, este segmento de edad comienza a ser socialmente reconocido como un grupo que goza de un "período de permisividad" que media entre la madurez psicofísica y la madurez social, y que consiste en una preparación progresiva hacia la vida adulta. Se trata de un privilegio para ciertos jóvenes aquellos que pertenecen a sectores sociales relativamente acomodados- que pueden dedicar un período de tiempo al estudio y postergar exigencias vinculadas a un ingreso pleno a la madurez social, en su sentido económico, laboral y reproductivo (Margulis y Urresti, 1998).

Así, mientras la madurez psicosexual distingue a los jóvenes de los niños, este período de "moratoria psicosocial" (Erikson, 1976) los diferencia del "adulto" como categoría de reconocimiento social, definido bajo estas 
coordenadas epocales como "alguien que ha establecido su vida al margen de su familia de origen, que se auto sustenta, que ha constituido su propia familia, que tiene hijos, que ha definido exitosamente -después de prepararse para elloun destino laboral" (Urresti, 2003: 3). De este modo, la transición a la vida adulta se presenta como un proceso de integración social protagonizado por un nuevo segmento de edad -los jóvenes- y compuesto por una serie de vías sociales que, a medida que se transitan y se completan, conducirían a la adultez: del estudio al trabajo, de la dependencia económica familiar a la independencia económica, del hogar de origen al hogar propio, de una conformación afectiva experimental a una pareja definitiva y, por último, de ocupar el lugar de hijo a ocupar el lugar de padre.

Este modo de concebir la juventud como un período de moratoria y preparación para la vida adulta se remonta a la influencia que la psicología evolutiva ejerció en los inicios de la perspectiva sociológica y, en particular, al enfoque funcionalista de los ciclos vitales. Este enfoque tuvo particular influencia en los primeros estudios socio-demográficos sobre el proceso de transición a la vida adulta. En oposición a este abordaje de la juventud como período de espera, se desarrollaron los estudios pioneros sobre identidades y culturas juveniles que destacaban el carácter productivo de los jóvenes como nueva generación: un grupo de edad que participa en los procesos de creación y circulación cultural, en tensión con el mundo de los adultos. Estos estudios han criticado al enfoque funcionalista de los ciclos vitales por su carácter adultocéntrico, en tanto la juventud sería concebida desde un carácter negativo, como un estatus incompleto y provisional sólo evaluable positivamente en función de la asunción de roles propiamente adultos (entre otros, Chaves, 2010; Krauskopf, 2007; Reguillo, 2000).

Por otra parte, desde la mitad de la década de 1970, en un contexto de globalización del mundo de vida y del sistema económico, una serie de investigaciones cuestionaron el enfoque socio-demográfico clásico y 
126 La "casa de la amistad": Modos de construir y significar el hogar propio en jóvenes de la Ciudad de Buenos Aires

comenzaron a analizar el proceso de transición a la vida adulta desde la perspectiva del propio sujeto (Casal, 1996; Furlong y Cartmel, 1997; Galland, 1995). En su conjunto, estos estudios plantearon la necesidad de desarrollar una perspectiva más sociológica sobre el tema de la transición que considere tanto los factores macro como microsociales que configuran las múltiples trayectorias posibles. Esta perspectiva, conocida como "sociología de la transición", suele referirse a la "transición a la vida adulta" en términos de "transición a la emancipación familiar plena", para distinguirse del concepto psicologisista de la vida adulta (como sinónimo de madurez). Esta mirada define la juventud desde el enfoque biográfico como un "tramo dentro de la biografía, que va desde la emergencia de la pubertad física hasta la adquisición de la emancipación familiar plena" (Casal, Merino y Quesada, 2006: 28). Desde aquí, el estudio de la transición se deriva del estudio de la juventud, es decir, del abordaje de ese tramo de la biografía, en función de los "itinerarios" y "trayectorias" que describen sus protagonistas -los jóvenes- hacia la emancipación familiar plena. De acuerdo con este enfoque, la transición juvenil involucra una articulación compleja de procesos de formación, inserción profesional y emancipación familiar.

En la sociedad contemporánea ${ }^{8}$, los procesos de transición juvenil se han visto profundamente alterados. Con esto nos referimos a que esa serie de pasos o vías que conducirían, socialmente hablando, de una edad -la infancia- a otra -la adultez- atraviesan un proceso de rearticulación significativo a partir de la década de 1970. Tanto en Europa como en Latinoamérica, los estudios especializados señalan que las etapas que en las sociedades modernas se manifestaban como determinantes trayectos de pasaje hacia la vida adulta trabajo consolidado, hogar propio, familia e hijos- en la actualidad se prorrogan, se interrumpen e incluso llegan a desestructurarse (Casal, 1996;

${ }^{8}$ Esta sociedad marcada por la incertidumbre ha recibido múltiples nombres: "posindustrial", "modernidad radical", "segunda modernidad", "posmodernidad", entre otros. 
Furlong y Cartmel, 1997; Galland, 1995; Reguillo, 1999). Las trayectorias biográficas de los jóvenes evidencian una flexibilización de las normas en cuanto al tiempo social y las secuencias de los eventos que configuran el modelo de transición a la vida adulta (Coubès y Zenteno, 2004; Mora Salas y Oliveira, 2009). En términos generales, estos estudios destacan la mayor permanencia en el sistema educativo, la complejización del paso de la educación al trabajo, dadas las dificultades para lograr una inserción laboral estable, y la postergación en la edad de establecer parejas y tener hijos (Bendit et al., 2008; Dávila y Ghiardo, 2005 y 2012; Roberti, 2016). Estos cambios en las trayectorias de los jóvenes se vinculan con la nueva estructura social marcada por las tendencias hacia la incertidumbre y la vulnerabilidad y, a la vez, con las transformaciones socioculturales ligadas a los procesos de individualización del curso de vida (Galland, 2001).

Ahora bien, mientras en sociedades relativamente homogéneas la experiencia de esas transiciones juveniles tenderían a ser similares para todos los miembros de cada generación; en sociedades desiguales, tanto en términos socioeconómicos como culturales o regionales, se presentan transiciones distintas que podrán variar en sus modalidades y velocidades de acuerdo con las presiones materiales y las pautas culturales a las que se esté expuesto (Balardini y Miranda, 2000; Dávila y Ghiardo, 2012). Al respecto, entre las primeras investigaciones referidas a Latinoamérica, Figueira (CEPAL, 1998) subraya la existencia de dos modelos de emancipación claramente diferenciados en su calendario según el nivel socioeconómico. De acuerdo con este autor, el retraso de los jóvenes provenientes de familias con mayores recursos convive con la emancipación temprana para los jóvenes de estratos bajos. Por ello, hoy en día se prefiere hablar de juventudes, en plural, antes que de juventud y de transiciones en lugar de un modelo único estandarizado.

En el caso de los jóvenes pertenecientes a familias de sectores medios y medios-altos, consideramos que la noción de "moratoria social", tal como la 
128 La "casa de la amistad": Modos de construir y significar el hogar propio en jóvenes de la Ciudad de Buenos Aires

conciben Margulis y Urresti (2008), constituye una herramienta analítica válida para referirnos a sus experiencias vitales. Resulta posible plantear que estos jóvenes con mayores posibilidades económicas no sólo disponen de un "crédito temporal" significativamente más extenso que el de las generaciones mayores, sino que, además, atraviesan una etapa de "moratoria social", es decir, un período más prolongado orientado a la capacitación y la experimentación en el que se postergan las responsabilidades tradicionalmente asociadas a la vida adulta ${ }^{9}$. En este artículo, nos enfocamos en las experiencias de estos jóvenes de sectores medios, entre quienes se conjugan la "moratoria vital" y la "moratoria social”, y analizamos cómo este tipo particular de condición juvenil interviene en los modos de construir y significar un hogar propio.

\section{ESTRATEgia METOdológica}

Los resultados aquí presentados forman parte de una investigación de mayor amplitud sobre las experiencias juveniles de salida del hogar de origen y construcción de un hogar propio en Buenos Aires. El enfoque metodológico utilizado es cualitativo-interpretativo. Al privilegiar la percepción de los actores y la comprensión del sentido de sus prácticas desde la perspectiva de los participantes (Sautu, 2004), esta estrategia resulta pertinente para explorar las vivencias de los jóvenes e indagar sus modos de significar el hogar propio.

El universo de estudio se circunscribió a varones y mujeres jóvenes de familias de sectores medios de la CABA. Las investigaciones en la Argentina caracterizan a estos sectores por sus niveles medios y medios-altos de instrucción (Sautu, 2016; Svampa, 2001),y por su tipo de ocupación laboral, ya sean dueños de pequeñas empresas, profesionales, técnicos y jefes, trabajadores

9 Cabe advertir que emplear la categoría de "moratoria social" para analizar experiencias de los jóvenes de sectores medios y medios-altos no implica definir a la juventud como período de preparación, sino destacar que, entre estos jóvenes, se evidencia una tendencia a postergar ciertos roles asociados a la vida adulta, como la formación de una pareja y una familia propia. 
administrativos o de comercio (Benza, 2016; Sautu, 2016).Decidimos detenernos en este grupo social ya que los estudios socio-demográficos locales advierten en ellos las tendencias de cambio y registran la mayor presencia de arreglos de convivencia horizontales.

A los fines metodológicos, consideramos jóvenes de sectores medios a quienes han alcanzado un nivel educativo igual o mayor al del colegio secundario completo, cuyos padres poseen trabajos de media o alta cualificación y cuyo nivel educativo también es igual o superior al del colegio secundario completo ${ }^{10}$. Asimismo, si bien esta categoría "juventud" define un grupo de edad, no se la puede demarcar con la exactitud que suponen los criterios etarios; como ya señalamos, sus límites son variables y sus fronteras son sociales antes que meramente etarias. En este sentido, los criterios de edad para enmarcar el período de la juventud son convenciones, es decir, están socialmente construidos. En la Argentina, tanto el INDEC como la Dirección General de Políticas de Juventud establecen los límites de la etapa joven entre los 15 y los 29 años. Dentro de esta franja, distinguen tres subgrupos: 15 a 19, 20 a 24 y 25 a 29. Mientras el primero define a los "adolescentes"; los dos siguientes, a los “jóvenes". Aquí adoptamos como universo de observación privilegiado al segmento de edad comprendido entre los 20 a 29 años, aunque sin excluir la posibilidad de incorporar otros a partir del trabajo de campo.

La principal técnica de recolección de datos consistió en la entrevista en profundidad orientada biográficamente. Esta herramienta resulta pertinente para registrar los discursos de los actores acerca de sus experiencias, percepciones y valoraciones, y reconstruir los significados que los propios protagonistas construyen de los sucesos de su vida (Sautu, 2004). El trabajo de campo se

\footnotetext{
${ }^{10}$ Respecto del régimen de escolaridad, en la CABA se inicia el nivel primario a partir de los 6 años de edad, e incluye un total de siete grados. Luego de los 13 años comienza el ciclo denominado secundario, que cuenta con un total de cinco años. A partir de los 18 años comienza el ciclo superior (terciario) o universitario (Ferraris y Martínez Salgado, 2015).
} 
130 La "casa de la amistad": Modos de construir y significar el hogar propio en jóvenes de la Ciudad de Buenos Aires

realizó en dos etapas. La primera se desarrolló entre los meses de septiembre y diciembre de 2013; la segunda, entre septiembre y diciembre de 2014. Con una duración aproximada de dos horas, las entrevistas se organizaron a partir de ejes temáticos que giraban en torno a las experiencias y las significaciones de los jóvenes sobre el proceso de salida del hogar de origen y la construcción de un nuevo hogar. Estos ejes no eran restrictivos sino que más bien funcionaban como disparadores para la conversación. Cuando se realizaron en los hogares actuales de los jóvenes, también se efectuaron observaciones de las características de la vivienda y del barrio de residencia ${ }^{11}$.

La investigación se sustenta sobre la base de una muestra intencional, conformada a través del método bola de nieve. Seleccionamos casos que consideramos típicos o representativos; no buscamos representatividad estadística de la población general de la cual provienen los entrevistados, sino comprender los modos en que los actores atraviesan experiencias. La cantidad de informantes se estableció siguiendo el criterio de saturación de la información. Dentro de este marco, la muestra quedó conformada por 20 jóvenes-10 varones y 10 mujeres-, que tienen entre 24 y 29 años, y se fueron de su hogar de origen entre el 2009 y el 2013. Todos los jóvenes entrevistados ${ }^{12}$ han cursado carreras universitarias; la mayoría completó sus estudios, y algunos -los más jóvenes- continúan cursando; varios de los que finalizaron la universidad iniciaron estudios de posgrado. En cuanto a su situación laboral, todos son activos, perciben ingresos y se desempeñan en empleos afines a sus estudios, ya sea en el Estado, en empresas privadas u organizaciones no

\footnotetext{
${ }^{11}$ Cabe advertir que, si bien priorizamos el abordaje cualitativo, el trabajo de campo ha sido complementado con fuentes secundarias de carácter cuantitativo para determinar ciertas características educativas, laborales y familiares de los sectores juveniles de la CABA y describir las condiciones de acceso a la vivienda en la Ciudad. Esta caracterización resultó útil para especificar el universo de estudio y conformar la muestra intencional.

${ }^{12}$ Para proteger la identidad de los informantes, modificamos de forma aleatoria los nombres, respetando el género de cada uno de ellos.
} 
gubernamentales, o de forma independiente. Respecto de su situación afectiva, ninguno de estos jóvenes está casado ni tiene hijos y la mitad está en pareja. En relación con la situación laboral de sus padres, algunos son dueños de Pequeñas y Medianas Empresas o directores en estudios contables o jurídicos propios; varios se desempeñan como empleados administrativos en empresas privadas o instituciones estatales y algunos ocupan allí puestos jerárquicos. Estos padres son dueños de la vivienda que habitan en la CABA.

\section{EXPERIENCIAS DE CONSTRUCCIÓN DE UN HOGAR CON AMIGOS}

\section{LA LLEGADA A LA VIVIENDA.}

Al explorar cómo estos jóvenes de sectores medios construyen un hogar propio, advertimos que los amigos conforman un "soporte relacional" (Martuccelli, 2007) fundamental para afrontar el desafío de abandonar la casa familiar de origen, no sólo por el apoyo emocional y afectivo, sino también por el apoyo material que representan para conseguir una vivienda y gestionar el hogar. En estos casos, el alquiler resulta la forma predominante. Nicolás relata que con sus dos amigos optaron por "vivir juntos" porque los tres se querían ir a "vivir solos". Al respecto, Tomás cuenta lo siguiente:

Esto empezó como un proyecto hace un año y medio, más o menos. Nosotros nos conocemos, somos un grupo de amigos. Desde hace cinco años que jugamos al fútbol. Y nos empezamos a juntar con otros que más o menos se conocían y se armó un grupo de catorce. A partir de ahí, siete u ocho, nos empezamos a hacer más amigos y de esos siete u ocho, ahora somos tres acá, que vivimos, que se dio que el año pasado, más o menos seis teníamos ganas de vivir solos. Entonces, dijimos, bueno, "solos" solos no se podía porque es muy caro. Y nos pareció una buena posibilidad, por ahora, de vivir con alguien: de a tres o de a dos. En ese 
132 La "casa de la amistad": Modos de construir y significar el hogar propio en jóvenes de la Ciudad de Buenos Aires

momento, eran tres porque, bueno, éramos tres los que nos queríamos ir justo en el mismo momento. (Tomás, 24 años)

La salida de la casa de origen se presenta como un proyecto colectivo en el que confluyen las expectativas de autonomía singulares y en el que la vivienda se consigue mediante un tipo de alianza juvenil. Los amigos operan como soportes relacionales confesables; al igual que ocurre con la pareja, las relaciones de amistad configuran “... un refugio que refuerza nuestra seguridad y autoestima, y que permite a tantos otros enfrentar los períodos difíciles de la vida" (Martuccelli, 2007: 93). Clara explica que "había un tema de gastos, no me daba la guita [el dinero] para irme sola de ningún modo”. La dificultad no residía únicamente en conseguir una casa, sino también en equiparla y sostenerla en el tiempo, teniendo en cuenta los costos mensuales que implica alquilar. Al hacerlo en conjunto, se "amortizaban" los gastos y, si un mes alguno no podía pagar, se ayudarían, señala Manuel. Esto le ocurrió a Nicolás, quien trabajaba free-lance y durante un mes no tuvo ingresos suficientes. Antes de mudarse, Nicolás sabía que esto podía ocurrir, pero sentía que, de alguna manera, "eso era parte del aprendizaje" y contaba con el apoyo de sus amigos. "Y fue lo que pasó, un mes no tuve la plata y se la pedí prestada a un amigo de los que vive conmigo", cuenta.

Este modo de salida del hogar se caracteriza por una asociación económica y residencial: los jóvenes comparten los gastos del contrato de alquiler y los gastos domésticos. Como señala Tomás, el alquiler se torna colectivo: "nos dividimos los gastos entre los tres". El contrato de locación también estaba "a nombre de los tres. Se decidió así para compartir responsabilidades", indica el joven. La inmobiliaria mediante la cual se hizo la transacción les pedía: “dos garantías comprobables en Capital Federal, un mes anticipado, uno de depósito y uno de comisión”. Cada integrante del grupo puso en común la suma de dinero solicitada que le correspondía. Si alguno "se bajaba", el proyecto de mudanza "se caía”, como destaca Nicolás. En el caso de 
Tomás, él puso todo el dinero inicial. "Los chicos me lo fueron devolviendo. Pero no me dieron la plata directo; se iba devolviendo en que yo no pagaba otras cosas", aclara. Para aquellos que no contaban con la garantía propietaria requerida por las inmobiliarias, asociarse también era la posibilidad de obtenerla. Agustín, por ejemplo, señala que él no conseguía garantía, pero "alguien puso la cara por ese tridente mágico que estábamos conformando y todos lo afrontamos con la responsabilidad que eso implicaba".

Los jóvenes entrevistados movilizan sus ingresos económicos individuales pero, en lugar de recurrir directamente al mercado, se asocian con otros jóvenes para "poner en común" los recursos económicos de cada uno. Esta movilización de soportes materiales (la actividad laboral) y afectivos (los amigos) es lo que les permite hacer frente al desafío de construir un hogar propio. La salida de la casa de origen se logra mediante la articulación de una instancia asociativa -basada en relaciones afectivas horizontales-y otra mercantil; a su vez, las operaciones mercantiles están atravesadas por el apoyo horizontal y la lógica colaborativa entre pares. En lugar de acudir a sus familias de origen, estos jóvenes recurren a sus amigos, esos "hermanos de generación" con quienes se comparte la temporalidad social, y por lo general el sector social de origen, para resolverla encrucijada de forma cooperativa.

Si bien el factor económico resulta clave para entender la asociación, lo cierto es que este modo de residencia "asociativo" se construye sobre la base de relaciones afectivas horizontales, caracterizadas por la confianza y la intimidad, con quienes se compartieron espacios de sociabilidad que preexisten al arreglo de convivencia y lo condicionan. Nicolás, por ejemplo, abandonó "el nido" a los 23 años, junto a dos amigos "de la misma escuela a la que fuimos al jardín, al primario y al secundario". Él cuenta que eran "amigos de toda la vida" y formaban "un triángulo equilátero perfecto". A partir de lo que tienen en común, aúnan esfuerzos mancomunados para construir de modo colectivo un hogar propio. El apoyo mutuo, la interdependencia, tiene la particularidad de 
134 La "casa de la amistad": Modos de construir y significar el hogar propio en jóvenes de la Ciudad de Buenos Aires

ofrecerles un manto de protección y, a la vez, una satisfacción de conseguirlo por sus "propios medios", como señala Tomás. Esto evidencia que el apoyo horizontal, aunque es sin dudas un soporte imprescindible, no es significado como dependencia sino como construcción de autonomía.

Los costos involucrados en el proyecto de salida de la casa de origen fueron discutidos y calculados en grupo sobre la base de las posibilidades económicas de cada uno. Nicolás cuenta que, antes de mudarse, "nos juntábamos en la casa de alguno y veíamos cuánta plata se gastaba en el departamento: alquiler, expensa, si faltaban cosas de cocina, muebles, y sumábamos las compras del supermercado, las más grandes, que eran para el mes". Sus decisiones en materia de vivienda, lejos de ser individuales, resultan de una deliberación colectiva basada en la experiencia generacional.

Paula y Clara recuerdan que acudieron a amigos y conocidos con experiencia en "vivir solos con amigos": "nosotras teníamos una amiga, que también vivía sola con dos amigas, entonces nos juntábamos para ver cómo era la idea. Y le fuimos preguntando las experiencias de qué era lo que por ahí nos podía aconsejar" (Paula).De esta manera, el grupo de amigos -futura unidad doméstica- fijaba un "tope máximo" por persona que incluía alquiler, expensas, servicios y comida, y en función de ello emprendía la búsqueda de la vivienda. En general, el criterio siempre fue el mismo: una habitación por persona. En este sentido, sus decisiones, antes que meramente económicas, están enmarcadas en y constituidas por el entramado de relaciones sociales de las que forman parte.

El equipamiento del hogar también constituyó una tarea colectiva, basada en regalos de la familia, el intercambio de objetos familiares usados y su puesta en común con los amigos. "Cada uno fue rescatando de la casa de los viejos lo que pudo y después, a medida que fue teniendo la posibilidad de comprarse algo mejor o algo más cómodo, más funcional, lo iba haciendo", relata Manuel. “¡Mi casa es un gran rejunte de un montón de cosas! Nada tiene 
que ver con nada", dice Clara. En este arreglo de convivencia, los objetos usados son la norma porque, como advierten los entrevistados, asumir de forma colectiva estas compras representaba una complicación. Los bienes que pueblan la casa de la amistad tienen una historia, provienen de otras casas familiares, les pertenecían a tíos, abuelos, padres o hermanos; así equipadas, son una suerte de casas collage.

Mi familia me regaló la heladera, que era como el problema principal. Después todo lo demás lo fuimos de rejunte [juntar]. (...)Yo tenía una cama de dos plazas que también era una cama de mi tía, creo, que había tenido mi hermana, que mi hermana después cuando se mudó se llevó la de mi mamá, que cambió la cama. Así, vueltas, y yo me quedé con la de mi tía. Luli tenía una cama prestada por la hermana también, que se había mudado con el novio, entonces tenían los dos camas, le quedó para ella. (Clara, 24 años)

En suma, en la casa de la amistad, los lazos afectivos entre amigos constituyen un soporte que permite afrontar el desafío de abandonar el hogar familiar de origen. Con los amigos se comparte dinero, garantía propietaria, objetos de equipamiento, información, contactos, entre otros y, a la vez, ellos mismos constituyen medios para acceder a una vivienda. Como vemos a continuación, este "vivir solo con amigos" se configura como un espacio de vida juvenil, de encuentros cotidianos, de intercambios y solidaridad. La casa misma resulta así un soporte para su construcción subjetiva.

\section{LA "FAMILIA AD HOC"}

Durante la adolescencia, el "grupo de pares" constituye un elemento decisivo para la configuración identitaria, en tanto conforma un espacio que permite la intimidad emocional y la confianza; en él, los adolescentes comparten sus intereses, sus gustos y preferencias, y establecen así sus primeras 
136 La "casa de la amistad": Modos de construir y significar el hogar propio en jóvenes de la Ciudad de Buenos Aires

identificaciones grupales (Krauskopf, 2007). Estos grupos de amigos constituyen "espacios propios", alejados temporalmente del control y la vigilancia del mundo adulto, que son centrales en los procesos de búsqueda de autonomía personal respecto de la familia de origen y los ámbitos de pertenencia heredados (Urresti, 2011). Ahora bien, este modo de estructurar la amistad va perdiendo fuerza cuando se deja atrás la etapa adolescente (Bidart, 1997; Gaviría, 2013; Krauskopf, 2007). Con las responsabilidades asociadas al "mundo adulto", tales como el trabajo y la familia propia, el entorno afectivo de las personas se va reconfigurando. De acuerdo con Bidart (1997: 241), a medida que se avanza en la edad, “... las relaciones están cada vez más aisladas las unas de las otras, se ve a las personas de manera separada y se funciona menos en grupo".

Consideramos que en la experiencia histórica de estos jóvenes de sectores medios, atravesada por la moratoria vital y social, la amistad sigue operando como un espacio propio fundamental para la construcción de la autonomía. En la vida de estos jóvenes, que valoran tanto la autonomía personal como la experimentación y el aprendizaje entre pares, la amistad tiene protagonismo por sobre la vida familiar, de tal manera que con los amigos se construye un nuevo grupo de convivencia, una "familia ad hoc", según Nicolás. "Es casi como seguir viviendo con tus viejos pero sin tus viejos. Es como vivir con tus hermanos, digamos, una cosa asî́”, cuenta Ignacio. De algún modo, el carácter afectivo de la casa de origen permea el hogar: sobre la nueva casa de la amistad se proyecta lo que ha sido vivido en la casa familiar.

Me parece que mudarme con amigos fue una especie de generar como una familia ad hoc, no sé cómo explicarlo...La dinámica que se generó en la casa fue una cosa bastante familiar. En realidad, terminamos reproduciendo algo muy parecido a lo que pasaba en mi casa, sólo que con otras personas. Por ahí, eso era, era repetir ese vínculo con Juani y 
con Manu, que no eran de mi familia... Era como poder elegir sobre esos vínculos, y que esos vínculos no eran tan agobiantes como sí pasaba en mi familia, digamos. Si dos días no venía a cenar, Juani no me iba a hacer ningún planteo; por ahí mi vieja sí. (Nicolás, 28 años)

Como señalan los entrevistados, el grado de confianza e intimidad permite generar una "dinámica más grupal". La mutua cooperación no sólo atraviesa la obtención de la vivienda y el equipamiento del hogar, sino también la administración de los gastos y de las tareas hogareñas. Estos jóvenes no forman hogares independientes dentro de una misma vivienda. La casa se gestiona en conjunto y, en verdad, es ese arreglo el que les permite emprender la salida de la casa de origen. Tomás, por ejemplo, señala que en el hogar "no hay un jefe. Está bien dividido todo". El relato de Nicolás enfatiza esta idea: "nunca una decisión se toma individualmente, en la medida de lo posible, nos esperamos a comer, hacemos actividades juntos... No somos tres personas que viven en una casa, digamos, somos como un grupo que vive en una casa". En este marco, los mensajes del tipo “¿a qué hora llegás?”, “¿alguno cena en casa hoy?, o "che, anoche no viniste, ¿qué onda?" no son vividos como obligaciones o formas de control, sino como parte del compañerismo o la fraternidad construida.

La casa de la amistad se presenta como un hogar donde construir las propias reglas de convivencia -en diálogo con los pares de generación y en tensión con los padres-, así como un espacio para aprender a valerse por sí mismo bajo una dinámica de juego y experimentación que contribuye a la configuración subjetiva del joven. En este sentido, la construcción de un hogar propio no refiere sólo a irse de la casa familiar de origen, sino también a construir un espacio intermedio, lúdico y de laboratorio, donde practicar la independencia y desarrollar su individualidad.

Pensamos que estas casas son una expresión material y simbólica de la amistad. En tanto espacio para la vida juvenil, el hogar propio conformado con 
138 La "casa de la amistad": Modos de construir y significar el hogar propio en jóvenes de la Ciudad de Buenos Aires

amigos opera como un ámbito de sociabilidad o de "socialidad", en términos de Maffesoli (1990) leído por Weiss: 'La 'socialidad' destaca el revivir de la comunidad, un actuar juntos guiado más por la emoción que por la razón (...) y la importancia de elementos lúdicos y dionisíacos en el vibrar juntos de un neotribalismo" (Weiss, 2007: 32). Sin embargo, estos espacios no se reducen a un "puro vibrar juntos" de manera momentánea. Como observa Weiss (2007) en su estudio sobre jóvenes y bachillerato en México, tanto en las conversaciones con sus amigos como en sus "diálogos internos", los jóvenes despliegan una reflexividad sobre su propia vida, de manera tal que el contacto con esos otros significativos abre posibilidades de autoconocimiento y expresión. En este sentido, consideramos que los jóvenes desarrollan en el espacio íntimo del hogar importantes procesos reflexivos, de conciencia y de expresión de sí mismos, que son fundamentales para su construcción identitaria.

A diferencia de los vínculos familiares, los pares de generación comparten "códigos", experiencias y modos de percibir, de apreciar y clasificar que son propios (Urresti, 2011). Los entrevistados destacan que las decisiones hogareñas son consensuadas, es decir, surgen de la experiencia compartida y, como tal, expresan aquello que los jóvenes tienen en común: si "no hay quórum, si no hubo acuerdo, quedan ahî”, explica Tomás. En comparación con su casa de origen, Nicolás explica: "acá no hay reglas, bah, no es que no hay reglas, sino que las que hay son las mismas que yo prohibiría. O sea, no me vomités en la puerta del cuarto. O, si vomitás, limpiálo [risas]". Al "compartir los mismos hábitos" hacen "todo en conjunto", cuenta Agustín; de alguna manera, "suplantaba al núcleo familiar materno -o paterno en mi caso-, pero con otro nivel de decisión, digamos, con otro nivel de autonomía”, explica.

En la casa de la amistad, el "fondo común" o "pozo de la casa" aparece como modo preferencial de gestionar la convivencia. "Tenemos un pocito de la casa. Ponemos todos los meses. Juntamos para el alquiler y un poquito más, y ese poquito más va al pozo", cuenta Tomás. Los jóvenes suelen dividir entre 
"gastos personales" (por fuera del "matrimonio que teníamos nosotros tres" explica Agustín- y costeados con dinero personal) y "gastos de la casa" (compartidos y administrados con dinero común). Algunos hacen una "compra grande mensual" en el supermercado; otros realizan "compras comunes diarias" de forma individual y llevan un registro de los gastos. Ahora bien, como advierte Nicolás, y varios coinciden, "acá nunca hubo nada etiquetado en la heladera. O sea, yo sé que si Juani tiene aceitunas y se las termino, se va a enojar. Pero, bueno, está todo bien, al otro día voy y le compro otras aceitunas". Ante la pregunta de para qué usan ese dinero compartido, Tomás explica:

Para la comida de Víctor Hugo [el gato], para los artículos de limpieza, para Lili que viene una vez cada quince días a limpiar y para... ahora ya no pasa tanto, pero al principio se rompía algo y había que arreglarlo o decíamos 'bueno, juntemos durante un tiempo para pintar el living', que fue lo que pasó. $\mathrm{O}$ arreglar la cocina. Fuimos de a poquito arreglando la casa también con ese pozo. (...) Era como siempre para tener algo por alguna contingencia, pero no una fortuna. Tratamos de no tener mucha plata en el pozo. (Tomás, 24 años)

En general, los jóvenes expresan que cuentan con el apoyo de sus amigos en caso de necesitar dinero para algún consumo o no "llegar a pagar el alquiler", como le sucedió a Nicolás después de haber usado los ahorros para comprarse un auto. Entre amigos, el dinero prestado tiene un carácter simbólico, ya que opera como una suerte de comprobación de la amistad: ese dinero se apoya en el vínculo afectivo que, a la vez, lo fortalece pues refuerza compromisos y lealtades preexistentes. Como señalan los estudios sobre los usos y significados sociales del dinero, al circular en contextos afectivos, el dinero no constituye necesariamente un "ácido" que disuelve los lazos sociales (Zelizer, 2011), sino que “... por medio de él, estas relaciones se recrean, se mantienen, se significan y, también, se disputan" (Wilkis, 2013: 25). En ese compartir gastos (y dineros), se crea y recrea la cohesión afectiva. Tales 
140 La "casa de la amistad": Modos de construir y significar el hogar propio en jóvenes de la Ciudad de Buenos Aires

arreglos económicos devienen centrales para comprender la salida del hogar de origen porque, de no existir, estos jóvenes no podrían mantenerse en la vivienda, pues sus ingresos individuales no les resultan suficientes, al menos para irse de la casa de sus padres sin renunciar a la "calidad de vida" que tenían mientras vivían allí, como señala Manuel.

No quería... no es negociar, sino ceder la calidad de vida que tenía en mi casa [la de los padres]. No soy una persona de derrochar dinero, pero capaz me gusta ir a comer afuera una vez por semana, dos veces por semana, y lo sigo haciendo. O irme un fin de semana a la costa. (Manuel, 26 años)

Los jóvenes entrevistados revelan que la casa tiene, además, una "mística". Es "la casa de la amistad" o "la casa del pueblo", como destacan varios. "Todos los fines de semana es gente, gente circulando (...) Siempre: martes, miércoles, jueves, siempre te cae alguien, entonces tenés como esa mística también, ¿no? Es la casa de la amistad”, la define Agustín. En su relato, Ignacio enfatiza este carácter festivo: "como vivía con dos amigos de mi mismo estilo de vida, también era un espacio mucho más de fiesta. (...) Ellos dos compartían esta visión de disfrutarlo, de tratar de no descuidar algunos aspectos, pero de disfrutarlo a morir".

La casa de la amistad se presenta como una suerte de "hogar puente" que les permite dar el paso hacia la construcción de un hogar propio, aunque no sea la casa definitiva. Tomás la definió como "una casa de transición", ya que "no es la que, obviamente, querré toda la vida, pero como para practicar para ese momento me parecía que estaba bueno también no irse solo solo”. El siguiente testimonio de Nicolás muestra el hogar propio como un espacio de aprendizaje.

Los tres salíamos del nido materno y nos embarcábamos juntos en un proyecto que no teníamos ni idea de... ¡Yo no sabía hacer arroz, imaginate, no tenía la más pálida idea! "Voy a vivir a delivery”, decía. Fue como muy divertido, digamos, ¿no? Un poco aprender juntos, un 
poco que, bueno, alguno sabe de alguna cosa, entonces enseña; el otro sabe de otra cosa, entonces enseña. Pero, al ser en conjunto, fue como muy divertido, digamos, ¿no? Creo que si tuviese que haberlo hecho solo, por ahí hubiese encontrado una barrera un poco más dura. (Nicolás, 28 años)

Estos hogares dan cuenta del valor de la amistad en esta etapa de la vida en la que los jóvenes de sectores medios postergan ciertos compromisos familiares tradicionalmente asociados a la vida adulta. Sin hijos por criar ni padres por mantener y con más o menos ingresos, estos jóvenes construyen un hogar con sus amigos. En definitiva, estos jóvenes construyen junto a sus amigos un nuevo hogar que refuerza el vínculo afectivo al acentuar la intersubjetividad, la afinidad y el sentimiento compartido. Juntos, aprenden a "vivir solos".

\section{REFLEXIONES FINALES}

En la cotidianeidad de estos jóvenes de sectores medios los lazos de amistad se revelan con una presencia significativa. La salida del hogar familiar se logra mediante una solidaridad horizontal que atraviesa el acceso a la vivienda y modela la administración de la casa. La asociación con amigos habilita la salida de la casa de origen en términos afectivos y, a la vez, económicos. El apoyo mutuo bajo una lógica de cooperación -el gasto compartido y el "pozo común"- permite afrontar los costos de una vivienda que no sería posible afrontar de forma individual. Este modo de construir un hogar propio está signado por el tipo particular de condición juvenil, pues resulta de la mayor intensidad del crédito temporal y del crédito social.

Ahora bien, la dificultad económica referida en los relatos, que motiva esta asociación residencial, no es un aspecto aislado, pues se inscribe en una determinada forma de vida. El dinero que los jóvenes consideran necesario para 
142 La "casa de la amistad": Modos de construir y significar el hogar propio en jóvenes de la Ciudad de Buenos Aires

mudarse resulta de evaluaciones subjetivas que dependen de gustos $\mathrm{y}$ preferencias, las cuales, lejos de ser individuales, están socialmente constituidas. Estos jóvenes de familias de sectores medios quieren irse de la casa de sus padres sin renunciar a su posición social de origen. De alguna manera, la casa de la amistad constituye una estrategia conservadora, ya que les permite independizarse y, a la vez, mantener ciertos consumos como las salidas a restaurantes, los viajes en las vacaciones, la empelada doméstica e, incluso, la compra de un auto.

La convivencia con los amigos bajo esta lógica cooperativa les ofrece un soporte material y afectivo, ya que, si bien supone gastos, también habilita el ahorro y la satisfacción de sus expectativas de estilo de vida. En definitiva, implica un particular modo de vida juvenil en el que la "moratoria vital" y la "moratoria social" configuran una etapa de experimentación y disfrute en el presente. Es de esperar que este tipo de alianza económica y residencial entre amigos motive una salida más temprana del hogar de origen, ya que requiere menos dinero y, a la vez, resulta atractiva en un contexto de mayor crédito temporal y social.

La salida de la casa de origen se presenta como un desafío en la experiencia de los jóvenes que, al ser atravesado, los afirma como sujetos. En los relatos se expresa un importante proceso de construcción identitaria signado por la adquisición de responsabilidades y capacidades para manejar asuntos de su vida cotidiana de los que antes se ocupaba su familia. Para estos jóvenes, la constitución de un hogar propio con amigos es un suceso crucial en su conformación subjetiva. La casa es un espacio de autonomía y, como tal, opera como elemento de construcción identitaria. En este sentido, resulta posible plantear que el proceso de salida del hogar familiar de origen y la construcción de un hogar propio "pone a prueba" a los jóvenes, en tanto los "hace trabajar" y les “crea problemas" (Martuccelli, 2007). 
Consideramos que la casa de la amistad puede ser comprendida como una expresión de los procesos socioculturales ligados a la individualización y a la flexibilización de las normas sociales que en el pasado sujetaban la vida de las personas, en tanto evidencia que -en el escenario contemporáneo, y en particular en la experiencia juvenil de sectores medios- no es requisito convivir con la pareja para irse de la casa de origen. Este tipo de experiencias habitacionales dan cuenta, "a escala de los individuos" (Martuccelli, 2007), de los cambios históricos en curso referidos a los modos de construir parejas y familias, y al valor que adquiere la realización personal en la sociedad contemporánea.

Sin embargo, aunque la búsqueda de la realización personal cobre centralidad, estos jóvenes no aspiran a una vida sin lazos. Como hemos visto, esta modalidad de salida de la casa de origen consolida una cotidianeidad con los amigos que resulta, en verdad, la conquista de una separación respecto de los padres. Las casas de estos jóvenes son lugares de encuentro y espacios de sociabilidad donde pocas veces concurren los adultos; una suerte de laboratorios donde la amistad se ejercita día a día. En tiempos de liquidez e hiperconectividad en que los vínculos parecen atravesados constantemente por la esfera virtual, los relatos de los jóvenes dan cuenta de esta necesidad de encontrarse, contenerse y cooperar.

\section{REFERENCIAS BIBLIOGRÁFICAS}

Baer, Luis, y Mark Kauw (2016). Mercado inmobiliario y acceso a la vivienda formal en la Ciudad de Buenos Aires, y su contexto metropolitano, entre 2003 y 2013. Revista EURE N 126.

Balardini, Sergio, y Ana Miranda (2000). Juventud, transiciones y permanencias. Pobres, Pobreza y Exclusión Social. Buenos Aires: CEIL CONICET.

Bendit, Rene, Marina Hahn, y Ana Miranda (2008). Los jóvenes y el futuro. Procesos de inclusión social y patrones de vulnerabilidad en un mundo globalizado. Buenos Aires: Prometeo. 
144 La "casa de la amistad": Modos de construir y significar el hogar propio en jóvenes de la Ciudad de Buenos Aires

Bidart, Claire (1997). L'amitié, un lien social. Paris: La Découverte.

Bourdieu, Pierre (2000). La "juventud" sólo es una palabra. Cuestiones de Sociología. Madrid: Istmo.

Busso, Mariana, y Pablo Ernesto Pérez (2015). Combinar trabajo y estudios superiores. ¿Un privilegio de jóvenes de sectores de altos ingresos? Población y Sociedad Vol. 22 (1)

Casal, Joaquim (1996). Modos emergentes de transición a la vida adulta en el umbral del siglo XXI: aproximación sucesiva, precariedad y desestructuración. Revista Española de Investigaciones Sociológicas $\mathrm{N}^{\mathrm{o}}$ 75.

Casal, Joaquim, Maribel García, Rafael Merino, y Miguel Ángel Quesada (2006). Aportaciones teóricas y metodológicas a la sociología de la juventud desde la perspectiva de la transición. Papers, Revista de Sociología $\mathrm{N}^{\circ} 79$.

Ciganda, Daniel e Ignacio Pardo (2014). Emancipación y formación de hogares entre los jóvenes uruguayos: las transformaciones recientes. Papeles de Población Vol. 20, № 82.

Chaves, Mariana (2010). Jóvenes, territorios y complicidades. Una antropología de la juventud urbana. Buenos Aires: Espacio Editorial.

Cosacov, Natalia (2014). Trayectorias residenciales y decisiones de localización residencial de hogares de clase media residentes en el barrio porteño de Caballito. Argumentos $\mathrm{N}^{\circ} 16$.

Coubès, Marie-Laure, y René Zenteno (2004). Transición hacia la vida adulta en el contexto mexicano: una discusión a partir del modelo normativo. En Marie-Laure Coubès, María Eugenia Zavala de Cosío y René Zenteno. Cambio demográfico y social en el México del siglo XX. Una perspectiva de historia de vida. México: El Colegio de la Frontera Norte.

Dávila, Oscar, Felipe Ghiardo, y Carlos Medrano (2005). Los desheredados: trayectoria de vida. Valparaíso: Ediciones CIDPA.

Dávila, Óscar y Felipe Ghiardo (2012). Transiciones a la vida adulta: generaciones y cambio social en Chile. Última Década $\mathrm{N}^{\mathrm{o}} 37$.

Echarri Cánovas, Carlos Javier, y Julieta Pérez Amador (2007). En tránsito hacia la adultez: eventos en el curso de vida de los jóvenes en México. Estudios Demográficos y Urbanos Vol. 22 № 1. México DF: El Colegio de México.

Erikson, Erik (1974). Identidad, Juventud y Crisis. Buenos Aires: Paidós.

Feixa, Carles (1998). De jóvenes, bandas y tribus. Barcelona: Ariel. 
Ferraris, Sabrina (2015).Vivir el momento justo. Transiciones a la adultez de mujeres del Área Metropolitana de Buenos Aires. Generaciones 1940 a 1979. Tesis doctoral, Facultad de Ciencias Sociales, Universidad de Buenos Aires. Buenos Aires: Mimeo.

Ferraris, Sabrina y Mario Martínez Salgado (2015). Entre la escuela y el trabajo. El tránsito a la vida adulta de los jóvenes en la Ciudad de Buenos Aires y el Distrito Federal. Estudios demográficos y urbanos 30 No 2.México DF: El Colegio de México.

Furlong, Andy, y Fred Cartmel (1997). Young people and Social Change: Individualisation and Risk in the Age of High Modernity. Buckingham: Open University Press.

Galland, Olivier (1985). Formes et transformations de l'entrée à la vie adulte. Sociologie du Travail $\mathrm{N}^{\mathrm{o}} 1$.

Galland, Olivier (2001). Sociologie de la jeunesse. Paris: Armand Collin Colection U Sociologies.

Gaviría, Sandra (2007). Juventud y familia en Francia y en España. Madrid: Centro de Investigaciones Sociológicas.

INDEC (2014). Censo Nacional de Población Hogares y Vivienda 2010. Año del Bicentenario.

Krauskopf, Dina (2004). Comprensión de la juventud. El ocaso del concepto de moratoria psicosocial. JOVENes Revista de Estudios sobre Juventud $\mathrm{N}^{\circ}$ 21.

Maffesoli, Michel (2004). El tiempo de las tribus. El ocaso del individualismo en las sociedades posmodernas. Madrid: Siglo XXI.

Mannheim, Karl (1993). El problema de las generaciones. Revista Española de Investigaciones Sociologícas $\mathrm{N}^{\circ} 62$.

Margulis, Mario, y Marcelo Urresti (1998). La construcción social de la condición de juventud. En AA.VV. Viviendo a toda: Jóvenes, territorios culturales y nuevas sensibilidades. Bogotá D.C: Siglo del Hombre Editores.

Margulis, Mario, y Marcelo Urresti (2008). La juventud es más que una palabra. En Mario Margulis. La juventud es más que una palabra. Buenos Aires: Biblos.

Martuccelli, Danilo (2007). Cambio de rumbo. La sociedad a escala del individuo. Santiago de Chile: LOM.

Martuccelli, Danilo y Kathya Araujo (2010). La individuación y el trabajo de los individuos. Educação e Pesquisa Vol. 36. 
146 La "casa de la amistad": Modos de construir y significar el hogar propio en jóvenes de la Ciudad de Buenos Aires

Mora Salas, Minor y Orlandina de Oliveira (2009). Los jóvenes en el inicio de la vida adulta: trayectorias, transiciones y subjetividades. Estudios Sociológicos XXVII, N 79.México DF: El Colegio de México.

Observatorio de la Juventud (2016). La conformación de un nuevo hogar. Boletín del Observatorio de la Juventud Año $3 \mathrm{~N}^{\circ}$ 1.Ciudad de Buenos Aires: Dirección General de Políticas Juventud.

Reguillo, Rossana (2000). Emergencia de culturas juveniles. Estrategias del desencanto. Buenos Aires: Norma.

Roberti, Eugenia (2016). Los sentidos (des)centrados del trabajo: Hacia una reconstrucción de los itinerarios típicos delineados por jóvenes. Última Década $\mathrm{N}^{\circ} 44$, Valparaíso: Ediciones CIDPA.

Sautu, Ruth (2004). Estilos y prácticas de la investigación biográfica. El método biográfico. La reconstrucción de la sociedad a partir de los testimonios de los actores. Buenos Aires: Editorial de Belgrano.

Sautu, Ruth (2016). La formación y la actualidad de la clase media argentina. En Gabriel Kessler: La sociedad argentina hoy. Radiografía de una nueva estructura. Buenos Aires: Siglo XXI.

Svampa, Maristella (2001). Los que ganaron. La vida en los countries y barrios privados. Buenos Aires: Biblos.

Urresti, Marcelo (2011). Adolescentes, jóvenes y socialización: entre resistencias, tensiones y emergencias». En María Ignez Costa Moreira y Márcia Stengel. Juventudes contemporáneas: un mosaico de posibilidades. pp. 43-66. Belo Horizonte: Editora PUC Minas.

Weiss, Eduardo (2007). Jóvenes y bachillerato en México: el proceso de subjetivación, el encuentro con los otros y la reflexividad. Propuesta Educativa $\mathrm{N}^{\circ} 32$.

Wilkis, Ariel (2015). Sociología moral del dinero en el mundo popular. Estudios sociológicos XXXIII $\mathrm{N}^{\circ}$ 99. México DF: El Colegio de México.

Zelizer, Viviana (2011). El significado social del dinero. Buenos Aires: Fondo de Cultura Económica.

Recepción de artículo: septiembre 2016

Fecha de aceptación: abril 2017 